\title{
Cartografia da Cultura Fronteiriça: A Sociedade Civil e a Promoção das Políticas Culturais
}

\author{
Cartografia de la Cultura Fronteriza: La Sociedad Civil e la Promoción \\ de las Políticas Culturales
}

\author{
Bruno César Alves Marcelino푸 Isac Morais Lages Marcelino²; Raicilane Barbosa de Jesus \\ Santana ${ }^{3}$ \\ 1brunomarcelino@claec.org, Centro Latino-Americano de Estudos em Cultura; \\ 2isacmorais@ claec.org, Centro Latino-Americano de Estudos em Cultura; \\ ${ }^{3}$ raicilanesantana@ claec.org, Centro Latino-Americano de Estudos em Cultura.
}

\begin{abstract}
Resumo
Este trabalho é uma apresentação dos resultados obtidos junto ao projeto de pesquisa Cartografia da Cultura Fronteiriça, financiado via Fundo de Apoio à Cultura do Estado do Rio Grande do Sul, o projeto teve como objetivo mapear e identificar as entidades e grupos culturais sediados nos municípios de Jaguarão e Arroio Grande/RS ambos integrantes da fronteira sul do estado, a metodologia ocorreu em três partes, na primeira ocorreu o levantamento e coleta de dados, a segunda foi a realização da pesquisa de campo e visita aos grupos e associações mapeadas e a terceira e última consistiu no tratamento dos dados e das informações coletadas, identificamos um total de dezessete grupos e entidades culturais e compreendemos como se dá a produção cultural nestes.
\end{abstract}

Palavras-Chave: Fronteira, Cultura, Sociedade, Cartografia.

\section{Resumen}

Este trabajo es una presentación de los resultados obtenidos del proyecto de investigación 'Cartografia da Cultura Fronteiriça', financiado a través del Fundo de Apoio a Cultura do Estado do Rio Grande do Sul, Brasil, el proyecto tuvo como objetivo mapear e identificar las entidades y grupos culturales con sede en los municipios de Jaguarão y Arroio Grande/RS ambos miembros de la frontera sur del estado, la metodología se produjeron en tres partes, la primera fue una recopilación de encuestas y datos, el segundo llevamos a cabo una investigación a campo y visitas a los grupos y asociaciones asignadas y la tercera fue el tratamiento final de las informaciones obtenidas, se identificaron un total de diecisiete grupos y organizaciones culturales y miramos entender cómo es la producción cultural en estos.

Palabras Clave: Frontera, Cultura, Sociedad, Cartografia. 


\section{Introdução}

O projeto em questão foi executado pelo Instituto Conexão Sociocultural, entidade criada por estudantes do curso de Bacharelado em Produção e Política Cultural da Universidade Federal do Pampa, campus Jaguarão, que agrega artistas, ativistas, técnicos e produtores em torno de ações voltadas para a promoção, expansão e difusão das políticas culturais através da elaboração e execução de projetos socioculturais. O principal produto foi um etnomapeamento das entidades e organizações socioculturais presentes na região da fronteira sul do Estado do Rio Grande do Sul, Brasil, tendo como base os municípios de Arroio Grande e Jaguarão.

O etnomapeamento consistiu no registro das dinâmicas socioculturais da região e foi compartilhado através da publicação de uma cartilha em formato de e-book, bem como com a inserção das informações no sistema de informações e indicadores culturais do Estado do Rio Grande do Sul o "Mapa Digital da Cultura RS". A pesquisa resultou em informações sobre grupos e entidades culturais das cidades mapeadas, tais como de grupos artísticos em seus diferentes segmentos, escolas de samba, escolas de dança dentre outros, proporcionando desta maneira, um diagnóstico parcial da cultura local.

O que se buscou foi oferecer ao público informações detalhadas sobre estas organizações culturais, promovendo o turismo cultural local, e subsidiando o Estado na elaboração de políticas públicas pertinentes aos segmentos culturais, através da formulação de diagnósticos do universo mapeado, desta forma, contribuiu-se para o fornecimento de informações que podem auxiliar na implementação de programas, projetos e ações que possam a curto, médio e longo prazo promover, valorizar e fomentar o desenvolvimento da cultura fronteiriça.

As informações servirão de ferramentas técnicas para a elaboração e o desenvolvimento de projetos e práticas na área da cultura que sejam mais conectadas com cada realidade identificada. $\mathrm{O}$ produto final desse processo de pesquisa permitiu identificar as demandas explícitas e ocultas de cada localidade, possibilitando ainda uma maior articulação entre os grupos e entidades culturais locais.

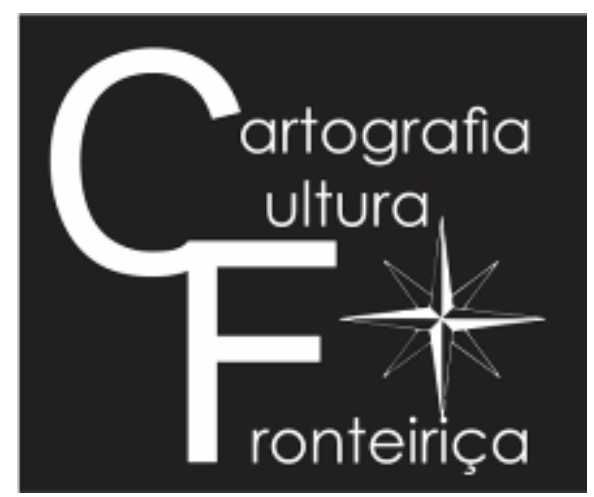

Figura 1 - Logo do Projeto

Fonte: Arquivo pessoal do autor 


\section{Metodologia}

A nossa metodologia de trabalho foi baseada nos estudos vinculados aos indicadores culturais, ligada a produção e a difusão cultural a partir de grupos e associações culturais presentes nas áreas físicas da fronteira do estado do Rio Grande do Sul com o Uruguai.

O trabalho foi dividido em três etapas, a primeira consistiu no levantamento e coleta de dados, a segunda etapa na pesquisa de campo propriamente dita, e visita aos grupos e associações mapeadas e a terceira e última etapa consistiu no tratamento dos dados e das informações coletadas durante a pesquisa.

A primeira etapa tomou por base cadastros existentes nas prefeituras, Cadastro Estadual de Produtores Culturais da Secretaria de Estado da Cultura, Ministério da Cultura, entre outros, informações sobre a existência de grupos, coletivos, pontos de cultura, associações e demais entidades que servissem de suporte para a construção de um banco de dados inicial.

$\mathrm{Na}$ segunda etapa com base nas informações coletadas na primeira, realizamos uma pesquisa de campo, visitando os grupos e associações culturais mapeadas. Utilizamos como método de estudo a aplicação de questionários para o corpo diretivo e para o público frequentador, priorizando as seguintes informações para a direção das entidades e grupos: localização e situação da sede do grupo; principais atividades artísticas e educacionais do grupo; principais parceiros e no que consistem essas parcerias; formação de profissionais no setor cultural e a forma de financiamento e de subsistência dos grupos. Objetivou-se traçar um perfil de como eles se conectam com outros grupos, a existência de outras conexões dentro de suas comunidades, a estrutura que dispõem estes grupos e como financiam e desenvolvem suas atividades.

Para o público frequentador dos grupos utilizamos um questionário priorizando as seguintes informações: idade e nível escolar; forma de deslocamento até o grupo ou associação; inclusão digital através do uso do microcomputador e acesso à internet; importância das atividades dos grupos para a comunidade; frequência a equipamentos culturais como teatros, cinemas, museus, biblioteca, ctg's e eventos artísticos como shows e apresentações musicais. Objetivou-se observar o perfil da pessoa que este grupo atende, a importância das atividades dos grupos e a relação de acessibilidade tanto aos meios de comunicação quanto a equipamentos culturais.

A terceira etapa consistiu no tratamento dos dados gerados através das informações coletadas pelos questionários e vivências nos grupos, entidades e associações pesquisadas. O resultado foi disponibilizado através da inserção dos dados nos sistemas de informações e indicadores culturais existentes em âmbito estadual e na construção de um livro em formato de e-book, que contém todas as 
informações adquiridas, como a quantidade de grupos culturais presentes na região, as atividades desenvolvidas por esses, os números de pessoas que trabalham nos grupos, as principais formas de divulgação adotadas pelos grupos, perfil das pessoas que frequentam os grupos, o custo que o grupo possui para executar suas atividades, a forma de captação dos recursos para execução das atividades, os bens culturais produzidos por eles. Durante a etapa três foram realizadas também, capacitações com grupos pesquisados através da disponibilização de cursos presenciais (oficinas) e palestras, que possibilitou o maior conhecimento e aquisição de experiência entre os agentes culturais e o público frequentador dos grupos e associações mapeados.

\section{Resultados}

Com este trabalho identificamos um total de dezessete grupos, entidades e/ou aparelhos culturais e compreendemos como se dá a produção cultural nestes. Do total dos grupos pesquisados há uma predominância de escolas de samba, correspondendo a 35,29\% das entidades pesquisadas. Notouse que estes grupos se sustentam de forma bastante precária visto que teriam de ter uma estrutura muito maior do que a que possuem de fato, além de que, em sua maioria estas entidades não conseguem dar continuidade ao trabalho durante todo o ano, em virtude de não terem subsídio para manter a instituição por todo este período. A maioria dos responsáveis ou dirigentes destes grupos tem capacitação jurídica e contábil insuficiente, além de pouca informação, não tomando conhecimento, por muitas vezes, de apoios possíveis que poderiam ter através de leis incentivos ou não sabendo como participar dos mesmos.

As escolas de dança correspondem a 17,64\% do total pesquisado. Estas entidades apresentam em sua maioria foco em atividades voltadas a uma época especial do ano, onde se preparam para eventos específicos dentro de um calendário pré-estabelecido. Percebeu-se que esta ocorrência se dá por conta de uma quase ausência de incentivos a estes grupos que em sua maioria sobrevivem através de apoios do comércio local e/ou incentivos dos próprios participantes destas entidades.

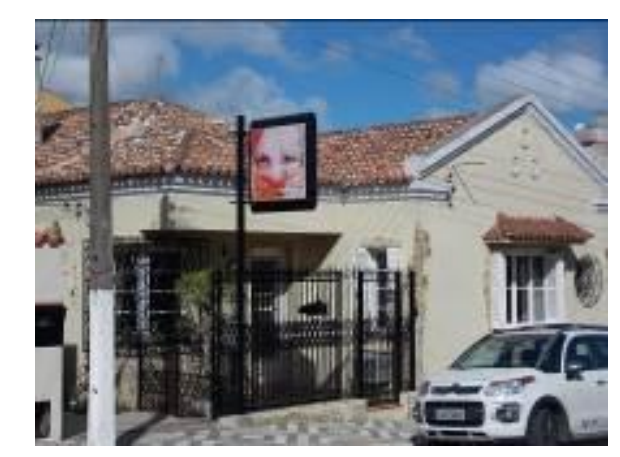

Figura 2 - Ayuni Escola de Dança

Fonte: Arquivo pessoal do autor 


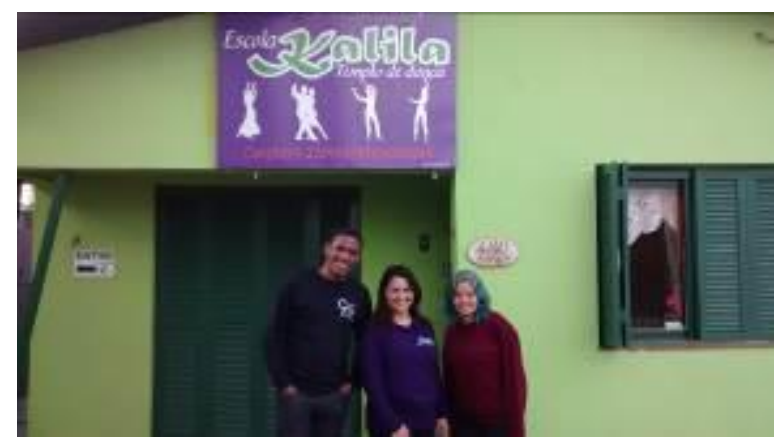

Figura 3 - Kalila Templo de Dança

Fonte: Arquivo pessoal do autor

Os demais grupos entrevistados totalizam 47,05\% dos pesquisados e são clubes sociais, sociedades culturais, confrarias, institutos esportivos culturais, associações de artesanato e instituições de formação política. A maioria das dificuldades enfrentadas por estas instituições são relacionadas a falta de estrutura adequada, capacitação deficiente dos coordenadores e dirigentes, pouca informação a respeito de leis de incentivo que possam apoiar a instituição e a falta ou pouco subsídio governamental e privado. Coletamos ainda informações sobre o funcionamento destes grupos e a relevância da atuação dos mesmos na comunidade em que estão situados.

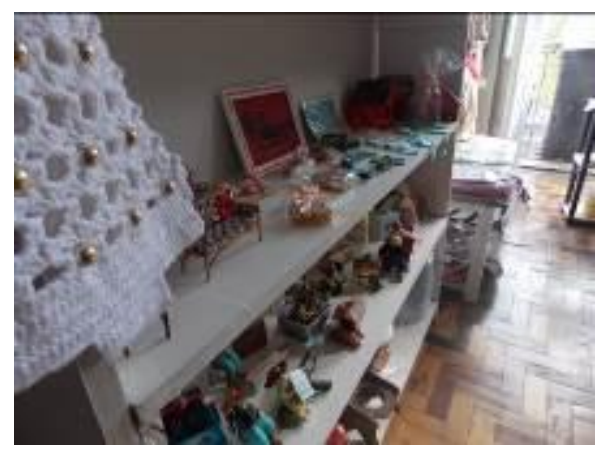

Figura 4 - Associação dos Artesãos de Jaguarão

Fonte: Arquivo pessoal do autor

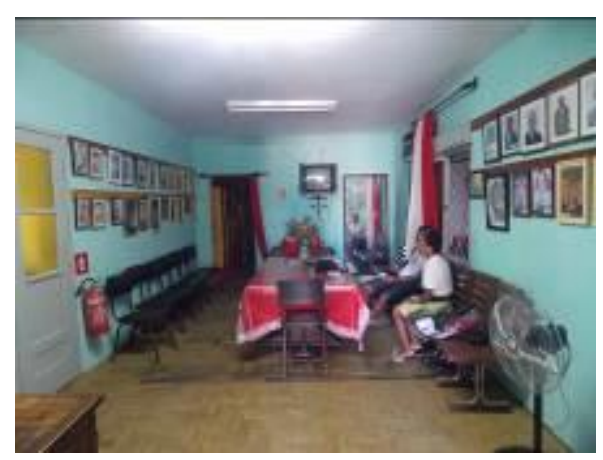

Figura 5 - Clube Social 24 de Agosto

Fonte: Arquivo pessoal do autor 
Ofereceu-se oficinas com temáticas voltadas a área cultural, como economia criativa e elaboração de projetos culturais afim de instruir minimamente os agentes culturais dos locais onde a pesquisa estava sendo executada. Isto porquê, o intuito do mapeamento não foi meramente uma coleta de informações descompromissada, mas sim o estabelecimento de uma rede de informações dessas entidades e uma formação com propósito de agregar aos agentes já atuantes em suas realidades locais maiores conhecimentos organizacionais e a respeito de leis de incentivo à cultura, por exemplo.

Levamos em consideração que apesar da frequente socialização, das grandes relações sociais e do intenso intercâmbio cultural presente nas regiões de fronteiras, estamos falando de uma região que sofre uma grande exclusão dos circuitos culturais, uma região que não tem políticas voltadas às suas especificidades e que dialoguem com as recorrentes transformações e transmutações advindas dos seus atributos históricos, geográficos, econômicos, políticos e sociais. Pensamos, antes de tudo, que estudamos entidades que muitas vezes ocupam o lugar do Estado na promoção de políticas culturais e sociais e principalmente na disponibilização de espaços de socialização e de convivência.

Um mapeamento cultural deve se construir como uma ferramenta de promoção dos bens, serviços e das entidades culturais, e não como uma ferramenta de transferência desses dados para a lógica de mercado. "Os bancos e seus componentes categoriais são seleções que permitem criar mapas úteis de uma realidade cada vez mais complexa e que nos permitam nela nos localizarmos de maneira pertinente, tomar decisões ou assumir posições." (YÚDICE, 2003, p.174), disponibilizamos as informações obtidas com a pesquisa como uma forma de potencializar as ações das instituições, manifestações e os grupos socioculturais que estão ali presentes.

Utilizamos a seguinte definição para nortear as premissas sobre etnomapeamentos:

Em linhas gerais os etnomapeamentos são estudos que partem da distinção entre grupos ou comunidades tradicionais que possuem uma especificidade sociocultural, a qual pode ser refletida na língua, na religião, nas maneiras de agir, nas instituições sociais ou nas distintas combinações desses fatores, expressando-se social e politicamente mediante uma identidade étnica. A identidade étnica surge do processo de auto-identificação (e não de fatores biológicos) dos respectivos membros do grupo étnico. Uma das bases materiais mais importantes de uma identidade étnica é seu território. Desta forma o território é o alicerce da sustentação física e da reprodução social, econômica e cultural de um grupo social (SOARES, 2010, p.14).

Trabalhamos no sentido de um etnomapeamento, que abarcou diversas características de um grupo ou entidade cultural. Compreendemos que foi necessária uma vivência em cada grupo ou entidade cultural identificada, analisando e observando a fundo suas práticas e ações. 


\section{Conclusão}

Compreendendo que a área cultural necessita de uma política pública eficaz e que atenda as especificidades desse campo, e entendendo também que antes de qualquer ação na área cultural se faz necessário um prévio panorama da situação das instituições, coletivos e espaços culturais, o mapeamento realizado pelo projeto Cartografia da Cultura Fronteiriça é uma importante ferramenta de subsídio para a atuação dos governos em suas três instâncias e da sociedade civil articulada. Fez se necessário conhecer os grupos, entidades, aparelhos e agentes culturais que atuam nas cenas locais dos municípios de Arroio Grande e Jaguarão, afim de integrar as informações destes espaços através de uma rede.

O projeto em questão vem ao encontro das metas do Plano Nacional de Cultura e em especial com o SNIIC - Sistema Nacional de Informações e Indicadores Culturais que tem como objetivo permitir que os agentes culturais e a sociedade como um todo possam ter acesso a informações do segmento cultural em um único lugar, fazendo com que o Brasil se equipare a outros países da América Latina e do mundo que já possuem banco de dados culturais. Ao longo do projeto iremos disponibilizamos cursos rápidos de capacitação nas áreas administrativas, da economia da cultura, elaboração e execução de projetos culturais entre outros que irão auxiliar na dinâmica de trabalho já praticada entre os grupos.

Cabe ressaltar que o projeto foi financiado com recursos do Governo do Estado do Rio Grande do Sul por meio da Secretaria de Estado da Cultura.

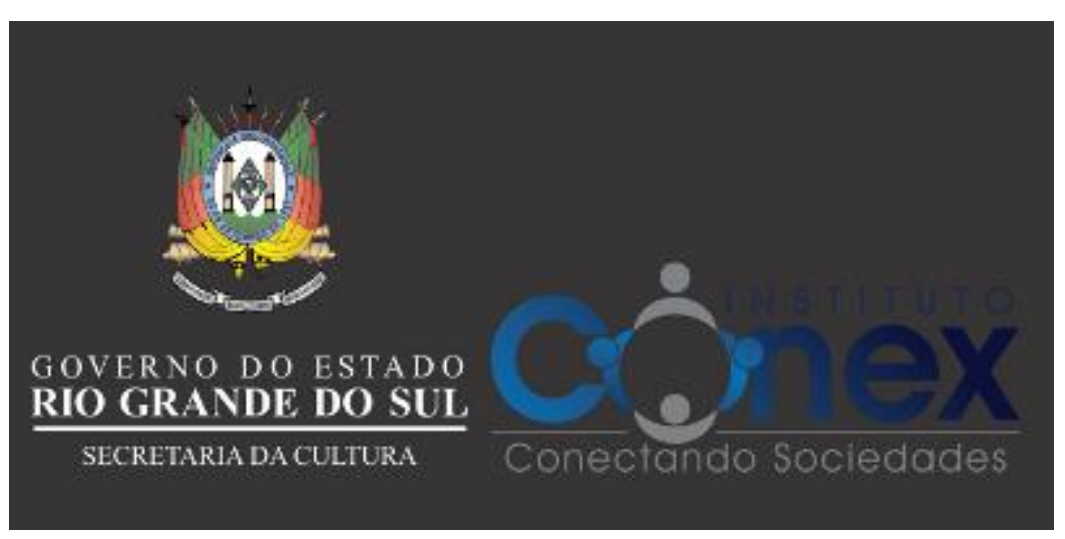

Figura 6 - Logos do Financiador e do Executor

Fonte: Arquivo pessoal do autor

\section{Referências}

ARANTES, Antônio Augusto; O que é cultura popular. 14.ed. São Paulo: Brasiliense, 2012. 
SANTOS, Boaventura de Souza. A universidade do século XXI. São Paulo: Cortez, 2005.

SEVERINO, Antonio Joaquim. Metodologia do Trabalho Científico. 23.ed. São Paulo: Cortez, 2007.

\section{Referências eletrônicas}

ALBAGLI, Sarita. Território e Territorialidades. In LAGES Vinícios; BRAGA, Christiano;

MORELLI, Gustavo (Org.). Territórios em movimento: cultura e identidade como estratégia de inserção competitiva. Rio de Janeiro: Relume Dumará/Brasília DF: Sebrae, 2004. 350p. Disponível em:

http://bis.sebrae.com.br/GestorRepositorio/ARQUIVOS_CHRONUS/bds/bds.nsf/E1C3CE6A43DBD B3203256FD6004907B7/\$File/NT00031436.pdf. Acesso em 02 de julho de 2015.

SOARES, Frederico dos Santos. Mapeamento cultural: uma proposta de leitura do espaço. Dissertação. Departamento de Geografia. Brasília: UNB, 2010. Disponível em: http://bdtd.bce.unb.br/tedesimplificado/tde busca/arquivo.php?codArquivo=6867. Acesso em 02 de julho de 2015.

YÚDICE, George. Para um banco de dados que sirva. In UNESCO (Org.). Políticas culturais para o desenvolvimento: uma base de dados para a cultura. Brasília: UNESCO Brasil, 2003. 236p. Disponível em:

http://unesdoc.unesco.org/images/0013/001318/131873por.pdf. Acesso em 02 de julho de 2015. 